\title{
THE WILLINGNESS TO ADOPT THE INTERNET OF THINGS (IoT) CONCEPTION IN TAIWAN'S CONSTRUCTION INDUSTRY
}

\author{
Jieh-Haur CHEN ${ }^{1}$, Nguyen Thi Thu HA², Hsing-Wei TAI ${ }^{3 *}$, Chao-An CHANG $^{4}$ \\ ${ }^{1}$ Department of Civil Engineering, Research Center of Smart Construction, National Central University, \\ Jhongli, 32001 Taoyuan, Taiwan \\ ${ }^{2}$ Department of Civil Engineering, National Central University, Jhongli, 32001 Taoyuan, Taiwan \\ ${ }^{3}$ School of Civil and Architectural Engineering, Shandong University of Technology, 255000 Zibo, China \\ ${ }^{4}$ Ruentex Engineering and Construction Corporation, 10492 Taipei, Taiwan
}

Received 16 July 2019; accepted 18 December 2019

\begin{abstract}
Internet of Things (IoT) conception has become a popular trend among industries. Many have already adopted the technology and put it into practice. IoT can incentive and change the way people conduct business in the construction industry. The objective of the research is to figure out the impact factors that influence practitioners' willingness to adopt IoT in Taiwan's construction industry. The hypothesis was developed based on a comprehensive literature review and the concept of the Unified Theory of Acceptance and Use of Technology (UTUAT). The UTUAT framework and hypotheses developed included 5 main hypotheses, 6 aspects and 33 stems. A pilot study aimed at experienced practitioners in the industry was carried out before the full-scale survey to adjust the stems. The adjusted questionnaire including 31 stems belonging to 7 aspects was then distributed to practitioners. A total of 282 valid questionnaires distributed were collected and 6 types of analysis (descriptive statistics, reliability, validity, t-test, one-way of variance, and structural equation modelling). The findings including (1) anticipated benefits significantly affect the users' willingness to adopt IoT; (2) anticipated efforts significantly affect the users' willingness to adopt IoT; (3) societal expectations significantly affect the users' willingness to adopt IoT.
\end{abstract}

Keywords: Internet of Things (IoT), Unified Theory of Acceptance and Use of Technology (UTAUT) model, Technology Acceptance Model (TAM), extension of the Technology Acceptance Model, construction industry, structural equation model.

\section{Introduction}

The Internet of Things (IoT) allows us to link to everyday objects and to identify and manage objects remotely, which could have a major impact on economic and social development. The IoT has already been widely incorporated in many fields, such as smart transportation, smart cities, smart homes, smart health, E-government, assisted living, agriculture, environmental protection, government work, public security, smart building, intelligent firefighting and industrial construction monitoring (Gubbia et al., 2013; Miorandi et al., 2012; Ray, 2016). Based on the forecast and analysis of future benefits of the IoT by the McKinsey Global Institute in 2015, the output value of these fields is expected to reach USD 3.9 trillion to 11.1 trillion in 2025 , accounting for $11 \%$ of the total GDP. In terms of building construction, the estimated output value is projected to reach USD 70 billion to 150 billion by 2025 (McKinsey Global Institute [MGI], 2015).

As demonstrated in the literature review, IoT has been already been applied by the construction industry for the development of smart homes, environmental monitoring and energy management (Gubbia et al., 2013; Miorandi et al., 2012; Ray, 2016). However, the willingness of users in the construction industry to incorporate IoT applications is generally not very high. The questions of concern are how to persuade practitioners in the construction industry to accept and find applications for this developing technology? What are the key factors influencing willingness to adopt? The purpose of this study is to identify and discuss the key factors affection the use of IoT in the construction industry. The unified theory of acceptance and

${ }^{*}$ Corresponding author. E-mail: rt007204@gmail.com 
use of technology (UTAUT) is adopted as the theoretical basis to discuss the influence of four variables (i.e. performance expectancy, effort expectancy, social influence and facilitating conditions) on use intention and use behavior. Statistical analysis on data derived from questionnaires is carried out to identify the key factors influencing willingness to adopt. This information will be provided to enterprise managers as an important reference indicator for decision making.

\section{Literature review}

\subsection{IoT and the construction industry}

The term IoT, first mentioned by Bill Gates in his book The Road Ahead, in 1995, did not attract the attention of the world at that time, because the necessary hardware, sensing equipment and wireless networks were not in place (Gates, 1995). Auto-ID Labs, founded in 1999 by Kevin Ashton, Executive Director of Auto-ID, is a leading global research network of academic laboratories, which has been able to develop the item identification system and concepts related to the IoT, on the basis of radio frequency identification (RFID) (Weiser et al., 1999). The development of the Bluetooth, Wi-Fi and big data service technologies, has allowed for integration with embedded sensors and actuator nodes (Sethi \& Sarangi, 2017), making the future of IoT-related industries promising. Lee et al. noted that the main technologies for the successful development of IoT products and services include RFID, wireless sensing networks (WSN), middleware, cloud computing and IoT-related application software (I. Lee \& K. Lee, 2015).

According to its conceptual definition, the IoT can be divided into layers, the sensing layer, the network layer and the application layer (Mahmoud et al., 2015). The sensing layer, also known as the sensor layer, forms the bottom layer in the architecture of the IoT. This layer mainly performs comprehensive sensing operations by making use of sensing components and devices to carry out data collection and monitoring of specific environments (Lin et al., 2017). The network layer, also known as the transmission layer, is an intermediate layer in the architecture of the IoT (Leo et al., 2014), whose main purpose is to connect the networks more widely and quickly, so that the data collected by the sensing layer can be reliably and securely transmitted to the specific target areas. This makes the network layer the most important layer in the architecture of the IoT (Al-Fuqaha et al., 2015). The application layer, also called the business layer (Tan \& Wang, 2010), is based on cloud computing and storage technology, analyzing and processing the data to support the platform layer and the application service layer. It also provides relevant intelligent services to support collaboration, sharing of information and interoperability across industries, applications and systems (Tan \& Wang, 2010). For example, the application layer can provide storage services where data received are incorporated into a database, or analysis services for direct evaluation of the received data to predict the future state of physical devices. There are many applications in this layer, each with different requirements, including the intelligent power grid, intelligent transportation and intelligent city (Wu et al., 2010; Viswannathen, 2015).

There has been little research concerning the application of the IoT to building construction. At present, companies mainly convert the data obtained into operational information for the prevention of work risk and to enhance work performance. The construction industry covers a wide range of work projects, and the required data needs to be recorded from planning to output of each project. These data include daily work reports, information transmitted by sensors, construction drawings, video data, etc. (Chen et al., 2016). Relevant research in the literature indicates that the content and quantity of the data obtained by companies can affect the conclusions and predictions obtained therefrom, for the establishment of intelligent systems for urban construction, measures for improvement of urban life, inspection of underground pipelines, construction of precast components, urban construction records and so on (Glaeser et al., 2018; Chi et al., 2017). Jia et al. (2019) analyzed the application of IoT technologies for buildings moving towards the critical goals of the construction of smart buildings, seeking to advance the implementation of IoT technologies in both the building construction and operating phases. In addition, others have attempted to develop IoT applications for the smart home, and to improve the acceptance and use of such applications (Alaa et al., 2017). In terms of improvement and management of construction projects, studies have found the application of IoT to be beneficial to achieving more efficient management of construction progress and production (Xu et al., 2018; Li et al., 2016, 2018; Zhong et al., 2017; Bhargav et al., 2015). The IoT has also been used in the field of construction waste. For example, Lu et al. $(2015,2016)$ introduced the application of big data for analysis and research on construction waste management and performance indicators.

\subsection{Discussion on Unified Theory of Acceptance and Use of Technology}

\subsubsection{Technology Acceptance Model (TAM)}

Past studies have shown that there are many factors that influence that affect the acceptance and adoption of a new technology by users which can be modeled, for example, by Davis's "Technology Acceptance Model" (TAM), as shown in Figure 1. In the TAM, the influences on user intention are described through two factors, perceived usefulness and perceived ease of use. The TAM theory is based on the influence of user beliefs on attitudes, influence of intent, and further influence on the actual behavior of technology adoption (Davis, 1989). Later, Venkatesh and Davis (2000) revised the TAM by omitting the variable of attitude and suggesting adding external variables to explore other influencing factors. The revised technol- 
ogy acceptance model (or TAM2) is more concise than the original model, and the explanatory power is more complete (Venkatesh \& Davis 2000).

The technology acceptance models assume that the perceived usefulness and perceived ease of use are the two key factors affecting the individual's attitude toward and willingness to use new information systems. Davis (1989) argues that perceived usefulness and perceived ease of use will affect the user's attitude to the use of a technology and thus their willingness to use it. He also suggests the same for the use of information systems. The main variables used in this model are described below:

(1) Perceived usefulness. This refers to the extent to which users believe that the use of specific information technology will improve their own performance. When the user perceives that the system is easy to use, they are inclined to believe that they can do more work using the technology system; the perceived usefulness is affected by the perceived ease of use and external variables.

(2) Perceived ease of use. This refers to the extent to which the specific information technology is perceived as easy to use. When the system is easier to use, the user's attitude toward the system will be more positive.

(3) Use attitude. The attitude of users is affected by perceived usefulness and ease of use.

(4) Willingness of use. The use of information systems is determined by the willingness of users to engage with it, and the willingness to use is affected by both the individual's attitude toward the use of technology and the perceived usefulness of that technology.

(5) External variables. Perceptions of usefulness and perceived ease of use are also affected by external variables, such as the external environment of the user's location, the characteristics of the system, convenience and the personal variables of the user.

\subsubsection{Extension of the Technology Acceptance Model}

There are many theories related to user acceptance of new technology in different field. Here, we briefly survey the relevant literature related to the extension from the above theories, and explores the introduction and application of the IoT to the construction industry. The following relevant theories are integrated.

\section{(1) Theory of Reasoned Action (TRA)}

The theory of reasoned action was proposed by Ajzen and Fishbein (1975) in the field of social psychology. The theory is used to explain and predict individual behavior. Its basic hypothesis is that people are rational. Before a person performs a certain behavior, he/she will first consider the meaning of the behavior itself and its result, and then decide whether to perform it or not. The theory has two basic hypotheses. One is that most behaviors are rational and controllable, and the other is that two factors (i.e. attitude toward the behavior and subjective norms) determine the intention toward certain behaviors (Ajzen \& Fishbein, 1975). They further suggested that individual behaviors can, to some extent, be judged by behavioral intention (BI). Behavioral intention determines the actual behavior (B), whereas attitude toward behavior (AT) and the subjective norm (SN) of the behavior affect the behavioral intention. Exogenous variables affect the user's attitude toward the behavior and the subjective norm of the behavior, through behavioral belief and evaluation (Ajzen \& Fishbein, 1980), see Figure 2.

\section{(2) Theory of Planned Behavior (TPB)}

Ajzen's theory of planned behavior is based on a further extension of the theory of reasoned action (Ajzen, 1985) to improve the situation of the theory of reasoned action. Since it is difficult to use the theory of reasoned action to predict and explain behaviors where individuals are affected by such factors as lack of coordination or lack of

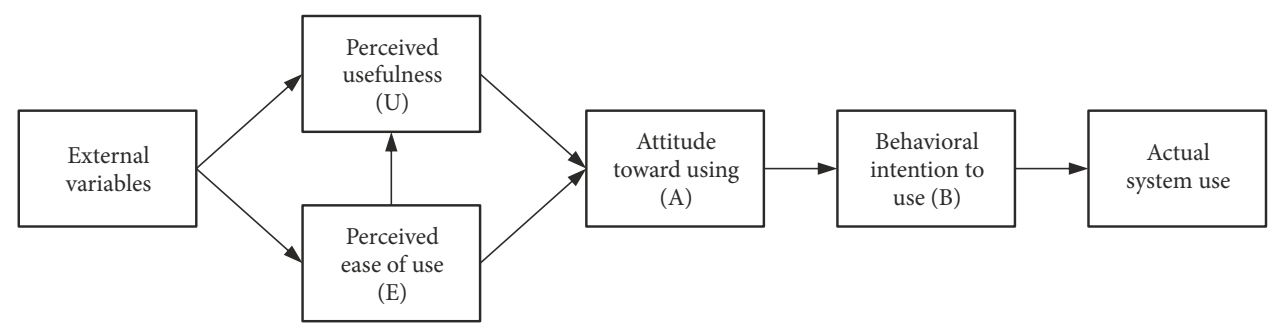

Figure 1. Technology Acceptance Model, TAM

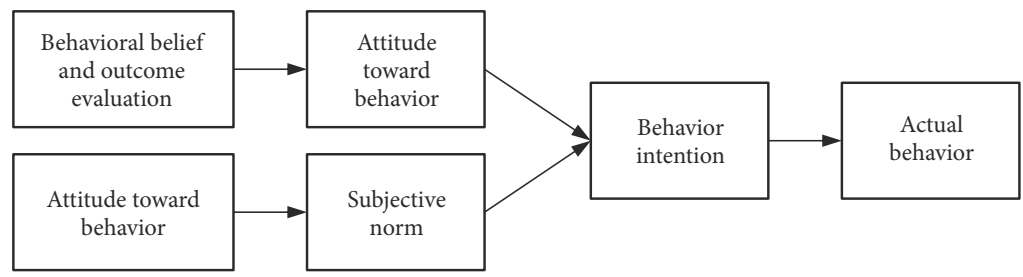

Figure 2. Theory of Reasoned Action Model, TRA 
self-ability, Ajzen (1991) developed the theory of planned behavior. This differs from rational action theory in that it holds that individual behavioral decisions are not completely controlled by the will, but also by resources and opportunities. Therefore, when using the theory to analyze behavioral intentions and actual behaviors, in addition to factors affecting behavioral attitudes and subjective norms, the factors influencing perceived behavioral control (PBC) must also be included. The extent to which a particular behavior is under an individual's control relates to the individual's perception of how easy it is to perform that behavior (Ajzen, 1991), see Figure 3.

\section{(3) Combined TAM and TPB (C-TAM-TPB)}

Taylor and Todd (1995a) developed a mixed model - a combination of the TAM and TPB (C-TAM-TPB), by combining the attitudes toward behavior and subjective norms as expressed in the theory of reasoned action (TRA) and theory of planned behavior (TPB) with perceived usefulness and other constructs of the technology acceptance model (TAM). Empirical results show that the C-TAMTPB model, which combines the technology acceptance model with the theory of planned behavior, offers a high degree of compatibility for understanding user adoption of new technology (Taylor \& Todd, 1995b). They divided users into two groups based on their experience. The results showed the behavioral intention of experienced users to be more obvious than that of inexperienced users: for experienced users, cognitive-behavioral adjustment affects behavioral intention more significantly in comparison to perceived usefulness; for inexperienced users, perceived usefulness affects behavioral intention more significantly (Taylor \& Todd, 1995c). The C-TAM-TPB model is shown in Figure 4.

\subsubsection{Unified Theory of Acceptance and Use of Technology (UTAUT)}

Venkatesh et al. (2003) developed the unified theory of acceptance and use of technology (UTAUT) after making a comparative analysis of different information technology acceptance models. The model has helped researchers to carry out relevant research, but looking forward to its continued development such as the inclusion of new constrtucts that affect user behavior in the future (Venkatesh et al., 2003). It was pointed out in that study that when users are faced with the choice of adopting new information technology or not, intention itself will affect that choice. Eight important model elements are integrated, including thirty-two concepts. The eight related theories are as follows: Theory of Reasoned Action (TRA), Theory of Planned Behavior (TPB), Technology Acceptance Model (TAM), Technology Acceptance Model-2 (TAM2), Combined TAM and TPB (C-TAM-TPB), Motivational Model (MM), Social Cognitive Theory (SCT), Model of PC Utilization (MPCU) and Innovation Diffusion Theory (IDT), see Figure 5.

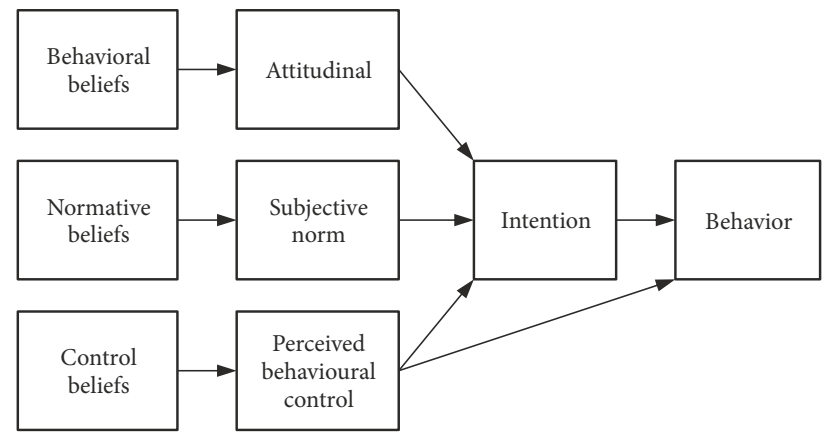

Figure 3. Theory of Planned Behavior Model, TPB

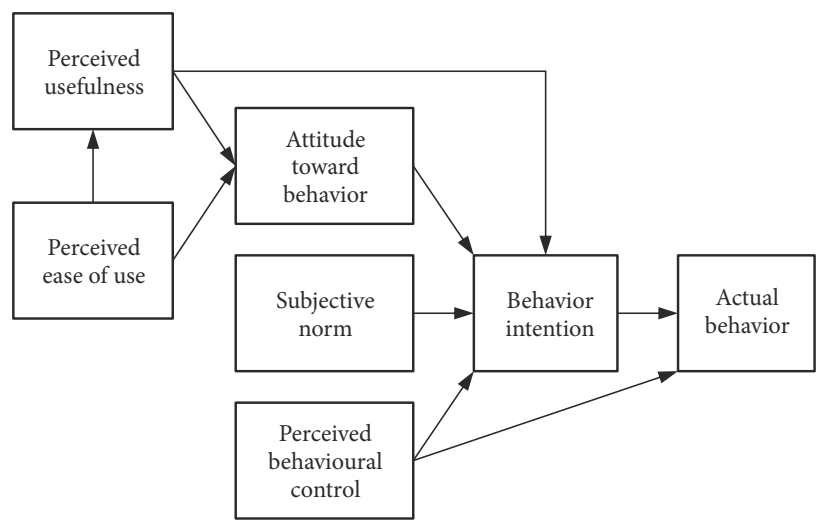

Figure 4. Combined TAM and TPB Model, C-TAM-TPB

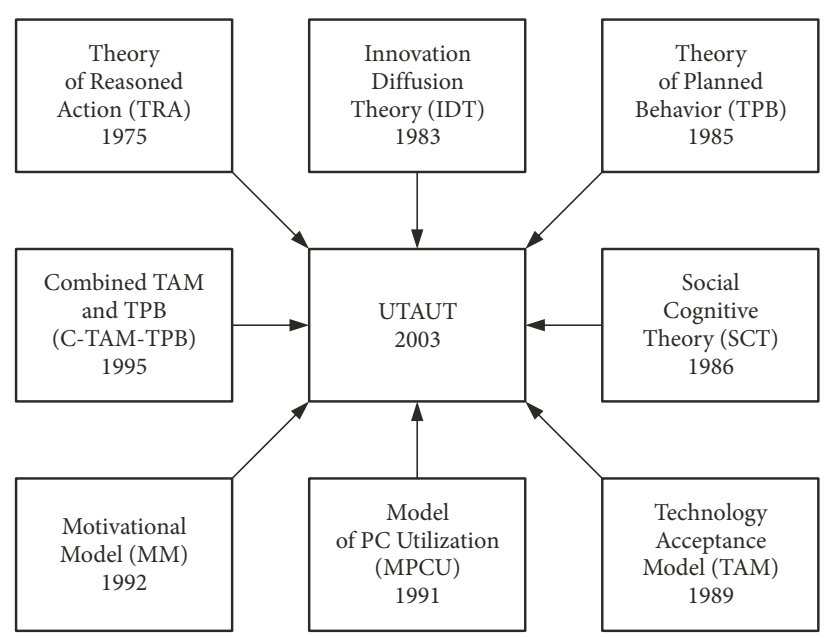

Figure 5. Conceptual model (Venkatesh et al., 2003)

The four main constructs of the UTAUT that affect the user's behavioral intention and actual behavior are performance expectancy, effort expectancy, social influence and facilitating conditions. These four main constructs and four control variables are obtained by integrating the various constructs considered most relevant from eight theoretical technology acceptance behavior-related (Venkatesh et al., 2003). Each key construct contains factors related to multiple theoretical models. The empirical results show that the new architecture has an explanatory power of $70 \%$ for usage behavior, which makes it the most effec- 
tive model at the present time. The four main constructs and their control variables are described below:

(1) Performance expectancy refers to the extent to which users believe that the system will help to improve work performance. The five sub-facets of performance expectancy are perceived usefulness, job fit, relative advantage, outcome expectation and extrinsic motivation. The relation between the user's own business and the system and whether it is substantially helpful for the work are important factors that affect the behavioral intention. In general, men, especially young men, pay more attention to performance expectancy than women (Venkatesh et al., 2003).

(2) Effort expectancy refers to how easy the system is to use. The existence of a sound user-friendly interactive interface with an easy-to-operate design affects how readily the system is accepted for use. The effort expectancy for any technological system is divided into three sub-factors: ease of use, complexity and perceived ease of use. The individual users' effort expectancies for information systems tend to vary with gender and age with women and older users paying more attention to the effort expectancies, but this changes with the accumulation of experience (Venkatesh et al., 2003).

(3) Social influence refers to the perceived degree of importance placed on the opinion of others who think the user should use the system. Social influence and behavioral intention are affected by various factors such as gender, age, experience and voluntariness of use. It contains the following three sub-facets: image, social factors and subjective norms. Image refers to an external manifestation that the individual believes is conducive to maintaining or promoting his/her status in the group (Moore \& Benbasat, 1991); social factors refer to the extent to which the reference groups for the individual are compatible with the mainstream culture (Bozionelos, 1996); subjective norm is the image that others confer on the person concerned.

(4) Facilitating conditions indicates the extent to which users believe their organization, technology and infrastructure can support the use of the systems (Venkatesh \& Davis, 2000). The three sub-facets of facilitating conditions are: perceived behavioral control, facilitating conditions and compatibility. Perceived behavioral control refers to the judgment of the user with respect to their perceived ability to operate the system; facilitating conditions refers to the technical assistance that provided in the current environment; compatibility refers to the consistency between the system and the perceived value of the organization (Venkatesh et al., 2003).

(5) Moderator variables. Among the four constructs, performance expectancy, effort expectancy and social influence are used to explore the factors influencing behavioral intention related to the use of information technology, whereas behavioral intention and facilitating conditions become the factors influencing actual behavior (Venkatesh et al., 2003). Among these factors, the moderator variables, such as gender, age, experience and voluntariness of use, may also have an influence. The research results indicate that the combined influence of two moderator variables will lead to a greater influence of the factors (Moore \& Benbasat, 1991; Lynott \& McCandless, 2000).

The constructs and sub-facets of the unified theory of acceptance and use of technology gleaned from the above literature review are summarized in Table 1.

\subsection{Brief summary}

The main objective of this research is to evaluate the willingness of construction industry personnel to introduce IoT applications. First, we use the technology acceptance model (TAM) proposed by Davis (1989), as the basis for examining user willingness to adopt new information systems, then integrates the theory of reasoned action (TRA) and the theory of planned behavior (TPB) proposed by scholars Ajzen $(1985,1991)$, Ajzen and Fishbein (1975, 1980). The combined TAM and TPB (C-TAM-TPB) and UTAUT are used to explore the key factors influencing the willingness of construction industry personnel to introduce IoT applications into their work. The results can be an important reference indicator for decision-making by enterprise management.

\section{Hypothesis development}

\subsection{Research hypothesis}

The four main constructs of the UTAUT that affect behavioral intentions, i.e. performance expectancy, effort expectancy, social influence and facilitating conditions (as direct variables), and the moderator variables that affect these four direct variables: gender, age, application experience and voluntariness are discussed. The structure generated by the variables is shown in Figure 6. (1) Direct variables: performance expectancy, effort expectancy, social influence and facilitating conditions. (2) Dependent variables: behavioral intention (stage I), actual behavior (stage II). (3) Moderator variables: gender, age, experience and voluntariness of use.

\subsubsection{Performance expectancy}

When users believe in and use a new information system and think the system will help to improve work performance, their attitude toward the use of the new system will be more positive (Davis, 1989; Taylor \& Todd, 1995b). If more than two systems are related to the work, users will have the intention to use the system with better expected results (Moore \& Benbasat, 1991). Venkatesh et al. (2003) also pointed out that performance expectancy has a positive impact on behavioral intention. Bozionelos (1996) showed that gender and age have a moderating effect with 
respect to the influence of performance expectancy on behavioral intention. This leads to the following hypotheses based on UTAUT:

H1: User performance expectancy has a positive impact on behavioral intention toward "IoT applications".

H1.1: User performance expectancy has a positive impact on behavioral intention toward "IoT applications" due to the moderator of gender differences.

H1.2: User performance expectancy has a positive impact on behavioral intention toward "IoT applications" due to the moderator of age differences.

\subsubsection{Effort expectancy}

When users think that a new system makes operations easier and that less effort is needed to use the system, they will be more willing to use it (Venkatesh et al., 2003; Agarwal \& Prasad, 1997; Szajna, 1996). Thompson et al. (1991) believe that, if an information system is difficult to understand and use, it will reduce the user's intention toward use. Other studies have shown that gender, age and experience have a moderating effect with respect to the influence of effort expectancy on behavioral intention (Venkatesh et al., 2003; Bozionelos, 1996; Lynott \&

Table 1. Definitions of the facets and sub-facets of the Unified Theory of Acceptance and Use of Technology

\begin{tabular}{|c|c|c|}
\hline Facet & Sub-facet & Definition \\
\hline \multirow{5}{*}{$\begin{array}{l}\text { Performance } \\
\text { expectancy }\end{array}$} & $\begin{array}{l}\text { Perceived Usefulness } \\
\text { (TAMTAM2/C-TAM-TPB) }\end{array}$ & $\begin{array}{l}\text { The extent to which users believe that use of the system can improve their work } \\
\text { performance }\end{array}$ \\
\hline & Extrinsic Motivation (MM) & $\begin{array}{l}\text { The feelings the users may want to express in respect of work improvement, salary, } \\
\text { and publicity }\end{array}$ \\
\hline & Job-fit (MPCU) & The extent to which the system may improve an individual's work performance \\
\hline & Relative Advantage (IDT) & New methods that will result in better performance values \\
\hline & $\begin{array}{l}\text { Outcome Expectations } \\
\text { (SCT) }\end{array}$ & $\begin{array}{l}\text { Related to the results of behaviour's, divided into performance expectancy and } \\
\text { personal expectancy }\end{array}$ \\
\hline \multirow{3}{*}{$\begin{array}{l}\text { Effort } \\
\text { expectancy }\end{array}$} & $\begin{array}{l}\text { Perceived Ease of Use } \\
\text { (TAM/TAM2) }\end{array}$ & The extent to which an individual believes the use of the system is simple \\
\hline & Complexity (MPCU) & The extent to which the system is difficult to understand and use \\
\hline & Ease of Use (IDT) & The extent to which users feel the new system is difficult to use \\
\hline \multirow{3}{*}{$\begin{array}{l}\text { Social } \\
\text { influence }\end{array}$} & $\begin{array}{l}\text { Subjective Norm } \\
\text { (TRA, TAM2, TPB/DPTB, } \\
\text { C-TAM/TPB) }\end{array}$ & $\begin{array}{l}\text { The extent that an individual feels what behavioral performance he/she should (or } \\
\text { should not) have according to the opinions of others }\end{array}$ \\
\hline & Social Factors (MPCU) & $\begin{array}{l}\text { An individual's extent of internalization of team culture and his/her agreement } \\
\text { with the team }\end{array}$ \\
\hline & Image (IDT) & $\begin{array}{l}\text { The extent to which use of the new system can enhance the impression of the user } \\
\text { to others }\end{array}$ \\
\hline \multirow{3}{*}{$\begin{array}{l}\text { Facilitating } \\
\text { conditions }\end{array}$} & $\begin{array}{l}\text { Perceived Behavioral Control } \\
\text { (TPB/DTPB .C-TAM-TPB) }\end{array}$ & Internal and external restrictions on his/her behavior that an individual is aware of \\
\hline & $\begin{array}{l}\text { Facilitating Conditions } \\
\text { (MPCU) }\end{array}$ & $\begin{array}{l}\text { Subjective factors that make people think it is easy to act or understand in its } \\
\text { environment }\end{array}$ \\
\hline & Compatibility (IDT) & $\begin{array}{l}\text { The extent to which users feel the value of the new system as well as the matching } \\
\text { degree of demand with experience }\end{array}$ \\
\hline
\end{tabular}

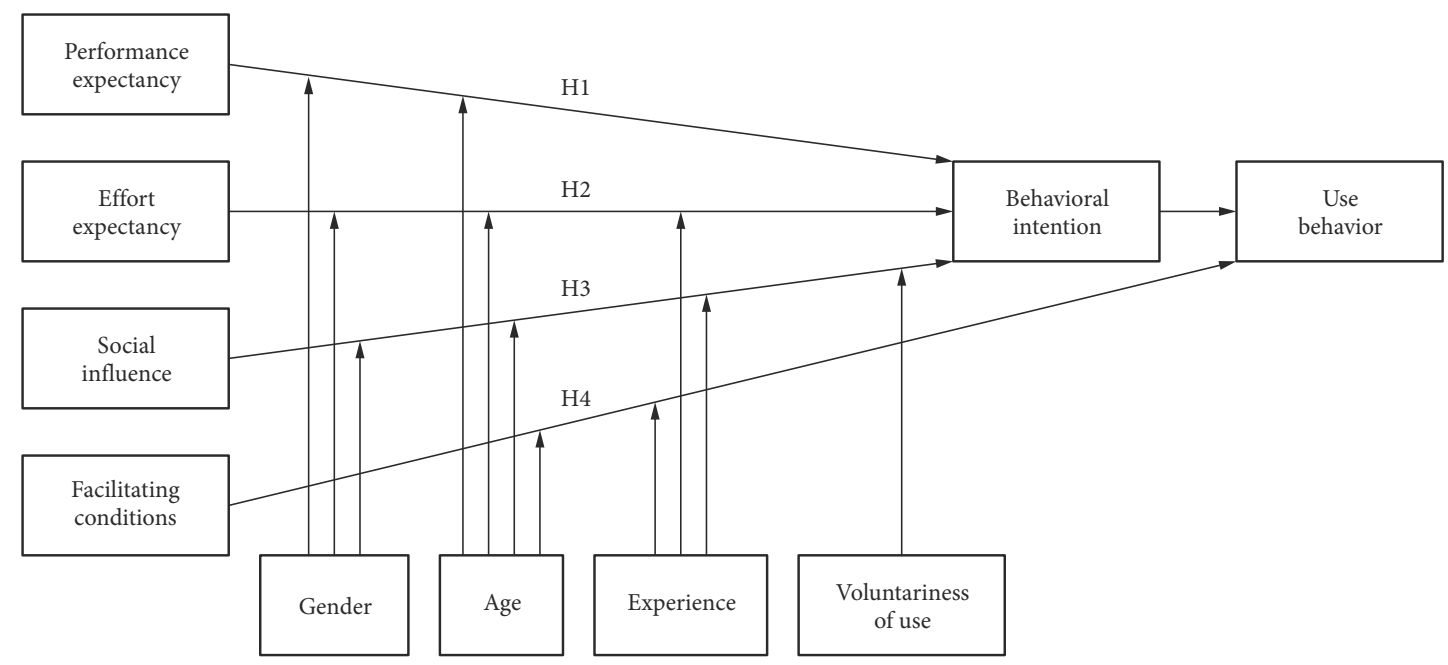

Figure 6. Diagram of the UTAUT architecture 
McCandless, 2000). The following research hypotheses based on UTAUT are developed:

H2: User effort expectancy has a positive impact on behavioral intention toward "IoT applications".

H2.1: User effort expectancy has a positive impact on behavioral intention toward "IoT applications" due to the moderator of gender differences.

H2.2: User effort expectancy has a positive impact on behavioral intention toward "IoT applications" due to the moderator of age differences.

H2.3: User effort expectancy has a positive impact on behavioral intention toward "IoT applications" due to the moderator of differences in experience.

\subsubsection{Social influence}

Ajzen and Fishbein (1975) noted that subjective norms (i.e. the external norms regarding how a person should act) arouse a person's willingness to act. Moore and Benbasat (1991) defined public image as referring to the specific image that a person believes to be conducive to maintaining or promoting his/her status in the group. Venkatesh et al. (2003) further considered that the image the user wants to project is related to the ideal images recognized by society or groups, which means that there is a significant positive correlation between image and model identity. Thompson et al. (1991) also believed that the subjective culture and specific protocols of a user's social environment will affect his/her intention to use an information system. According to the above studies, when a user perceives the subjective norm of the social environment and the key stakeholders think that the new system should be adopted, the user will be more willing to use the new system (Agarwal \& Prasad, 1997; Karahanna et al., 1999). Venkatesh et al. (2003) showed that gender, age and experience have a moderating effect on the impact of social influence on behavioral intention. This leads to the following hypotheses based on UTAUT:

H3: The social influence a user is subjected to has a positive impact on his/her behavioral intention toward the use of "IoT applications".

H3.1: The social influence a user is subject to has a positive impact on his/her behavioral intention toward the use of "IoT applications" due to the moderator of gender differences.

H3.2: The social influence a user is subject to has a positive impact on his/her behavioral intention toward the use of "IoT applications" due to the moderator of age differences.

H3.3: The social influence a user is subject to has a positive impact on his/her behavioral intention toward the use of "IoT applications" due to the moderator of experience differences.

H3.4: The social influence a user is subject to has a positive impact on his/her behavioral intention toward the use of "IoT applications" due to the moderator of voluntariness differences.

\subsubsection{Facilitating conditions}

The more ability/resources a user thinks that he/she has available to use the system, the more considerable, more frequent or more positive his/her actual use behavior will be (Taylor \& Todd, 1995b; Venkatesh et al., 2003). AlKhaldi and Wallace (1999) showed that facilitating conditions have a significant positive impact on the willingness of intellectual workers to use computers. Other studies have shown that gender, age and experience have a moderating effect with respect to the impact of social influence on actual behavior and facilitating conditions (Venkatesh et al., 2003; Lynott \& McCandless, 2000). This study derives the following hypotheses:

H4: The user's facilitating conditions have a positive impact on the actual behaviors toward the use of "IoT applications".

H4.1: The user's facilitating conditions have a positive impact on the actual behaviors toward the use of "IoT applications" due to the moderator of gender differences.

H4.2: The user's facilitating conditions have a positive impact on the actual behaviors toward the use of "IoT applications" due to the moderator of differences in experience.

\subsubsection{Behavioral intention}

Behavioral intention is the individual's perceived likelihood or "subjective probability that he or she will engage in a given behavior" (Armitage \& Conner, 2001). Karahanna et al. (1999) show that the actual use behavior of the individual is determined by the intention to use. This leads to the following hypothesis:

H5: User behavioral intention toward the "IoT applications" has a positive impact on actual behaviors.

\subsection{Definition of variables and measurement}

\subsubsection{Variable of personal background}

The personal background variable in this research is divided into five items: gender, age, application experience, frequency of use and voluntariness. Scale classification is conducted for each item from smaller to larger as follows:

(1) Gender: is divided into two, where the value of 1 refers to males and the value 2 refers to females.

(2) Age: from younger to older, age groups are divided as follows: 19 years old or below, $20-29$ years old, 30-39 years old, 40-49 years old, 50-59 years old, 60 years old or above, with values from 1 to 6 , respectively.

(3) Application experience: is divided into two, where the value 1 refers to "Experienced" and the value 2 refers to "Inexperienced".

(4) Duration of use: from low to high, where groups are divided as follows: "No contact", "Contact for half a year", "Contact for half a year to one year", "Contact for one year to two years", "Contact for more than two years", and are assigned values from 1 to 5 , respectively. 
(5) Voluntariness: This is the last variable of the construct, and is divided as follows: "Strongly disagree", "Disagree", "No comment", "Agree", and "Strongly agree", with values in order from 1 to 5 , respectively.

\subsubsection{Performance expectancy}

Performance expectancy is the extent to which users feel that using the system can help people improve performance. The expected performance refers to the extent to which users believe that the introduction of IoT applications will improve job performance. Table 2 shows the definitions used in this study which are based on the definitions of Venkatesh et al. (2003), with reference to other studies (Davis, 1989; Taylor \& Todd, 1995b, 1995c; Moore \& Benbasat, 1991). The expected performance indicators are modified to be suitable for measuring the response using five-point Likert scale (with responses ranging from "Strongly disagree" to "Strongly agree").

\subsubsection{Effort expectancy}

Effort expectancy refers to the amount of effort which he/ she believes they must exert to use the new system. Effort expectancy is thus related to how easy the user thinks it will be easy to use the IoT applications. The definitions are based on the work of Venkatesh et al. (2003), with reference to other studies (Davis, 1989; Agarwal \& Prasad, 1997; Szajna, 1996; Thompson et al., 1991), modified to obtain effort expectancy measurement items suitable for measurement with the five-point Likert scale (with responses ranging from "Strongly disagree" to "Strongly agree"), as shown in Table 3.

\subsubsection{Social influence}

Social influence refers to the influence felt by individuals from the persons whom they feel are important to themselves regarding the use of the new system. Social influence is the extent to which the user feels that others think that the user should introduce IoT applications. As shown in Table 4, the definition is based on the work of Venkatesh et al. (2003) and others (Moore \& Benbasat, 1991; Agarwal \& Prasad, 1997; Thompson et al., 1991; Ajzen \& Fishbein, 1975; Karahanna et al., 1999). The social influence measurement items are modified to be suitable for measurement with the five-point Likert scale (with responses ranging from "Strongly disagree" to "Strongly agree").

\subsubsection{Facilitating conditions}

Facilitating conditions refer to the extent to which an individual feels they receive support from the organization and other technology-related equipment in the use of the new systems. Facilitating conditions in this research refer to that the belief of the user that the infrastructure of the organization to which he/she belongs is sufficient to support the introduction of IoT applications, based on the definitions of Venkatesh et al. (2003), and others (Taylor \& Todd, 1995b, 1995c; Al-Khaldi \& Wallace, 1999). The facilitating condition measurement items are modified to be suitable for measurement with Likert's five-point scale (with responses ranging from "Strongly disagree" to "Strongly agree"), as shown in Table 5.

Table 2. Measurement items of performance expectancy

\begin{tabular}{|l|l|}
\hline \multicolumn{1}{|c|}{ Measurement items } & \multicolumn{1}{|c|}{ References } \\
\hline PE1 I think the introduction of IoT applications is helpful for my work & $\begin{array}{l}\text { Venkatesh et al. } \\
(2003) ; \\
\text { Davis (1989); } \\
\text { Moore and } \\
\text { Benbasat (1991); } \\
\text { Taylor and Todd } \\
\text { (1995b, 1995c) }\end{array}$ \\
\hline PE3 I think IoT applications can make my work easier & \\
\hline PE4 I think our staff can use IoT applications well & \\
\hline PE5 I think IoT applications can increase our company's competitiveness & \\
\hline PE6 I think IoT applications can help me work better & \\
\cline { 1 - 1 } PE7 I think IoT applications can help improve my work performance & \\
\hline PE8 I think IoT applications can help my work done efficiently & \\
\hline PE9 I think the introduction of IoT applications will increase the load on resources & \\
\hline PE10 If competitors are using IoT applications and have achieved good results; I think we should do the same & \\
\hline
\end{tabular}

Table 3. Measurement items of effort expectancy

\begin{tabular}{|c|c|}
\hline Measurement items & References \\
\hline EE1 I am clear about how to use the IoT & \multirow{5}{*}{$\begin{array}{l}\text { Venkatesh et al. (2003); } \\
\text { Davis (1989); } \\
\text { Agarwal and Prasad (1997); } \\
\text { Szajna (1996); } \\
\text { Thompson et al. (1991) }\end{array}$} \\
\hline EE2 For me, learning how to use IoT applications is not so complicated. & \\
\hline EE3 I think IoT applications are easy to use & \\
\hline $\begin{array}{l}\text { EE4 I think using IoT applications is convenient. EE1: I don't think the use of IoT applications is a } \\
\text { problem for me }\end{array}$ & \\
\hline EE5 I think IoT applications can help save my time in completing my work & \\
\hline
\end{tabular}


Table 4. Measurement items of social influence

\begin{tabular}{|c|c|}
\hline Measurement items & References \\
\hline SI1 I think the introduction of IoT applications into our company will be topical in the industry & \multirow{8}{*}{$\begin{array}{l}\text { Venkatesh et al. (2003); } \\
\text { Ajzen (1991); } \\
\text { Moore and Benbasat (1991); } \\
\text { Agarwal and Prasad (1997); } \\
\text { Thompson et al. (1991); } \\
\text { Karahanna et al. (1999) }\end{array}$} \\
\hline SI2 I don't think a company can go without IoT applications in the future & \\
\hline $\begin{array}{l}\text { SI3 With the rapid development of technology, the introduction of IoT applications into the } \\
\text { construction industry is a necessary process }\end{array}$ & \\
\hline SI4 I will use the related IoT applications as proposed by government policies & \\
\hline SI5 My supervisor highly supports my use of new technologies in work, such as the IoT & \\
\hline SI6 Our company fully supports the introduction of IoT & \\
\hline SI7 The owners who work with me think that I should introduce the IoT & \\
\hline SI8 The contractors who work with me think that I should introduce the IoT & \\
\hline
\end{tabular}

Table 5. Measurement items of facilitating conditions

\begin{tabular}{|c|c|}
\hline Measurement items & References \\
\hline FC1 I know something about IoT applications & \multirow{5}{*}{$\begin{array}{l}\text { Venkatesh et al. (2003); } \\
\text { Ajzen (1991); } \\
\text { Al-Khaldi and Wallace (1999) }\end{array}$} \\
\hline FC2 Our company's software and hardware facilities meet the needs of IoT applications & \\
\hline FC3 Our company provides sufficient education and training for the use of IoT applications & \\
\hline FC4 Certain people or groups can help me solve any problems with the IoT applications & \\
\hline FC5 My current working environment is suitable for the introduction of IoT applications & \\
\hline
\end{tabular}

\subsubsection{Behavioral intention}

Behavioral intention refers to the degree to which users will increase the duration and frequency of use of the new system. Specifically, it refers to the amount of positivity (like) or negativity (dislike) of the user with respect to the use of the IoT applications (Venkatesh et al., 2003; Bozionelos, 1996; Lynott \& McCandless, 2000). As shown in Table 6, the definitions are based on the work of Venkatesh et al. (2003) and others (Bozionelos, 1996; Lynott \& McCandless, 2000; Al-Khaldi \& Wallace, 1999). The behavioral intention measurement items are modified to be suitable for measurement with the five-point Likert scale (with responses ranging from "Strongly disagree" to "Strongly agree").

\subsubsection{Actual behavior}

As shown in Table 7, the measurement items of actual behavior are based on the work of Venkatesh et al. (2003) and Ajzen (1985, 1991).

\subsubsection{Voluntariness}

Voluntariness refers to the activeness or passiveness of the attitude of the individual toward the information system. Here, voluntariness refers to the extent to which the user is freely willing to use the IoT at work. The definitions are based on the work by Venkatesh et al. (2003). The voluntariness measurement items are modified to be suitable fir measurement with Likert's five-point scale (with responses ranging from "Strongly disagree" to "Strongly agree"), as shown in Table 8.
Table 6. Measurement items of behavioral intention

\begin{tabular}{|l|l|}
\hline \multicolumn{1}{|c|}{ Measurement items } & \multicolumn{1}{c|}{ References } \\
\hline $\begin{array}{ll}\text { BI1 I intend to use IoT applications } \\
\text { from now on }\end{array}$ & $\begin{array}{l}\text { Venkatesh et al. (2003); } \\
\text { Bozionelos (1996); } \\
\text { Lynott and McCandless } \\
\text { BI2 I will use IoT applications } \\
\text { frequently at work in the future }\end{array}$ \\
\cline { 1 - 1 } $\begin{array}{l}\text { BI3 My willingness to use IoT } \\
\text { applications is quite high }\end{array}$ & \\
\hline
\end{tabular}

Table 7. Measurement items of actual behavior

\begin{tabular}{|l|l|}
\hline \multicolumn{1}{|c|}{ Measurement items } & \multicolumn{1}{c|}{ References } \\
\hline $\begin{array}{l}\text { AB1 Have you ever used any related } \\
\text { IoT applications: Yes/No }\end{array}$ & $\begin{array}{l}\text { Venkatesh et al. (2003); } \\
\text { Ajzen (1985); } \\
\text { Ajzen (1991) }\end{array}$ \\
$\begin{array}{l}\text { AB2 Your actual history of using } \\
\text { IoT applications: no history/half a } \\
\text { year/one year/more than one year }\end{array}$ & \\
\hline
\end{tabular}

Table 8. Measurement item of willingness

\begin{tabular}{|l|l|}
\hline Measurement item & References \\
\hline $\begin{array}{l}\text { 1. I am willing to use the IoT } \\
\text { application at work }\end{array}$ & Venkatesh et al. (2003) \\
\hline
\end{tabular}

\subsection{Data analysis}

\subsubsection{Pilot testing of the questionnaire}

The factor of willingness to use with respect to the introduction of IoT systems into the construction industry is analyzed. A pilot test was carried out by distributing a 
total of 20 questionnaires to construction industry personnel. After removing responses where answers were incomplete or inconsistent, a total of 17 valid samples were collected and analyzed with the SPSS18.0 statistical software. The Cronbach's $\alpha$ coefficient was used as an indicator of the reliability of the analysis of the items and to measure the consistency and stability of the question items. Comparison of the Cronbach's $\alpha$ coefficient values obtained with improper question items not deleted and deleted was made. 6 question items that fell within the "behavior intention" and the control variables "actual behavior" and "voluntariness" were not included in the reliability measurement. The other deleted improper questions items included 2 under the sub-facet of performance expectancy, 1 under the sub-facet of effort expectancy, and items under the sub-facet of social influence. The Cronbach's $\alpha$ values of all constructs reached 0.875 , as shown in Table 9, indicating a significant level of reliability of the formal questionnaires used in this research.

In terms of validity, in order to ensure the correct presentation of the meaning of the original scales, we asked 9 IoT-related experts and scholars (including 3 professors, 2 doctoral students, and 4 industry leaders) to conscientiously discuss, deliberate and give recommendations on the content and text of the questionnaire. Therefore, the content validity and face validity of this research questionnaire have a significant level of validity.

\subsubsection{Discussion of the variables of demographic statistics with respect to IoT applications}

The data collection methods included paper-based, E-mail and online questionnaires distributed to individuals in the above-related fields. Online questionnaires were distributed using Google's questionnaire distribution tool. The questionnaires were distributed for a period from December 10, 2018, to December 29, 2018, a total of 20 days.

After the data samples were collected from the responses, a review was carried out. After deleting improper sample data, a total of 308 questionnaires were collected, with 282 valid questionnaires remaining after the deletion of 26 invalid questionnaires. The characteristics of the collected sample data are shown in Table 10.

\subsection{Hypothesis verification of the structural equation model}

The AMOS software is used in this study as a tool for analyzing the structural equation model to verify the hypothesis of UTAUT. A confirmatory factor analysis (CFA) of the measurement model must be performed prior to path analysis, so that the measurement data can estimate the correct path factor. According to the theory, after confirmatory factor analysis, the model needs to be modified by deleting improper disturbance variables in the relationship, and the reliability, validity and model fit of the modified model are verified. The model structure is shown in Figure 7.
Table 9. Reliability analysis before and after the deletion of measurement items

\begin{tabular}{|l|c|c|}
\hline \multicolumn{1}{|c|}{ Facet } & $\begin{array}{c}\text { Cronbach's } \alpha \text { value } \\
\text { before the deletion of } \\
\text { measurement items }\end{array}$ & $\begin{array}{c}\text { Cronbach's } \alpha \text { value } \\
\text { after the deletion of } \\
\text { measurement items }\end{array}$ \\
\hline $\begin{array}{l}\text { Performance } \\
\text { expectancy }\end{array}$ & 0.678 & 0.875 \\
\hline $\begin{array}{l}\text { Effort } \\
\text { expectancy }\end{array}$ & 0.884 & 0.933 \\
\hline $\begin{array}{l}\text { Social } \\
\text { influence }\end{array}$ & 0.839 & 0.902 \\
\hline $\begin{array}{l}\text { Facilitating } \\
\text { conditions }\end{array}$ & 0.918 & 0.918 \\
\hline
\end{tabular}

Table 10. Analysis of sample feature

\begin{tabular}{|c|c|c|c|}
\hline \multicolumn{2}{|c|}{ Sample Feature } & Quantity & Percentage \\
\hline \multirow{2}{*}{ Gender } & Male & 220 & $78 \%$ \\
\hline & Female & 62 & $22 \%$ \\
\hline \multirow{4}{*}{ Age } & $20-29$ & 138 & $49 \%$ \\
\hline & $30-39$ & 51 & $18 \%$ \\
\hline & $40-49$ & 82 & $29 \%$ \\
\hline & $50-59$ & 11 & $4 \%$ \\
\hline \multirow{3}{*}{$\begin{array}{l}\text { Education } \\
\text { level }\end{array}$} & $\begin{array}{l}\text { High school degree } \\
\text { or below }\end{array}$ & 20 & $7 \%$ \\
\hline & University degree & 135 & $48 \%$ \\
\hline & $\begin{array}{l}\text { Research degree or } \\
\text { above }\end{array}$ & 127 & $45 \%$ \\
\hline \multirow{6}{*}{ Position } & $\begin{array}{l}\text { Senior associate or } \\
\text { above }\end{array}$ & 22 & $8 \%$ \\
\hline & $\begin{array}{l}\text { Manager or deputy } \\
\text { manager }\end{array}$ & 20 & $7 \%$ \\
\hline & Section manager & 23 & $8 \%$ \\
\hline & Engineer & 121 & $43 \%$ \\
\hline & Staff & 51 & $18 \%$ \\
\hline & others & 45 & $16 \%$ \\
\hline \multirow{2}{*}{ Experience } & Yes & 116 & $41 \%$ \\
\hline & No & 166 & $59 \%$ \\
\hline \multirow{5}{*}{$\begin{array}{l}\text { Contact } \\
\text { time }\end{array}$} & Never & 150 & $53 \%$ \\
\hline & Half a year or below & 56 & $20 \%$ \\
\hline & Half a year $\sim$ one year & 39 & $14 \%$ \\
\hline & one year $\sim$ two years & 37 & $13 \%$ \\
\hline & two years or above & 0 & $0 \%$ \\
\hline \multirow{5}{*}{ Willingness } & Strongly agree & 42 & $15 \%$ \\
\hline & Agree & 180 & $64 \%$ \\
\hline & Neutral & 57 & $20 \%$ \\
\hline & Disagree agree & 0 & $0 \%$ \\
\hline & Strongly disagree & 3 & $1 \%$ \\
\hline
\end{tabular}

In this research, the reliability and validity of the model are measured using the combined reliability (CR) and average variance extracted (AVE). The combined reliability is the composition of the reliability of all measurement variables. An acceptable value is 0.7 (Hair et al., 1998; 


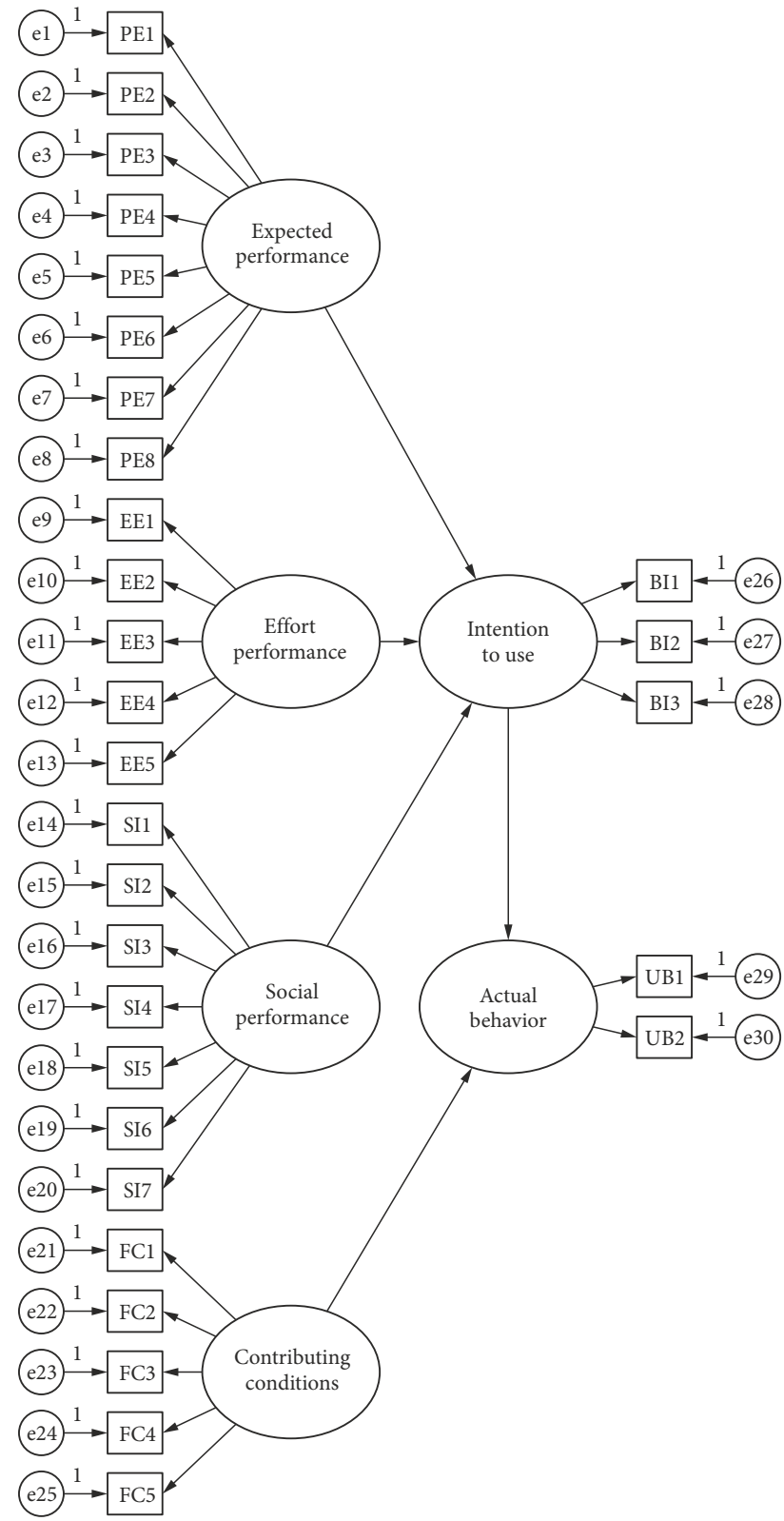

Figure 7. Architecture of the AMOS model

Jöreskog, 1993), and the higher the value, the higher the internal consistency. The AVE value is used to calculate the explanatory power of the measurement variables for the variation of the potential variable. Fornell and Larcker (1981) suggested that the standard value must be greater than 0.5. When the AVE value is higher, it indicates that the potential variable has a higher reliability and convergence validity. After the deletion of those items whose factor loading was less than 0.5 , there were 19 remaining items, as shown in Table 11. After the deletion, the combined reliability obtained was greater than 0.780 , and the AVE representing the validity is above 0.687 , indicating a significant level of reliability and validity.

In terms of the fit index, we use the criteria of Bagozzi and Yi (1988) for the model fit criteria. The main fit indices include the chi-square value $\left(\chi^{2}\right)$, degree of freedom (Df),
Table 11. CFA reliability analysis after the deletion of measurement items

\begin{tabular}{|c|c|c|c|c|c|}
\hline Facet & Variables & $\begin{array}{l}\text { Factor } \\
\text { loadings }\end{array}$ & $\mathrm{R} 2$ & $\begin{array}{l}\text { CR } \\
\text { (composite } \\
\text { reliability) }\end{array}$ & $\begin{array}{c}\text { AVE } \\
\text { (Average } \\
\text { Variance } \\
\text { Extracted) }\end{array}$ \\
\hline \multirow{4}{*}{ 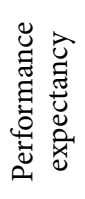 } & PE1 & 0.72 & 0.52 & \multirow{4}{*}{0.808} & \multirow{4}{*}{0.715} \\
\hline & PE2 & 0.76 & 0.58 & & \\
\hline & PE3 & 0.69 & 0.48 & & \\
\hline & $\mathrm{PE} 4$ & 0.69 & 0.48 & & \\
\hline \multirow{4}{*}{ 莺 } & EE1 & 0.60 & 0.36 & \multirow{4}{*}{0.787} & \multirow{4}{*}{0.689} \\
\hline & EE2 & 0.77 & 0.59 & & \\
\hline & EE3 & 0.53 & 0.28 & & \\
\hline & EE5 & 0.85 & 0.72 & & \\
\hline \multirow{3}{*}{ 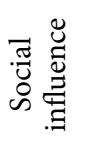 } & SI2 & 0.90 & 0.81 & \multirow{3}{*}{0.820} & \multirow{3}{*}{0.767} \\
\hline & SI3 & 0.86 & 0.74 & & \\
\hline & SI4 & 0.54 & 0.29 & & \\
\hline \multirow{3}{*}{ 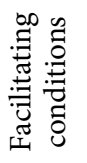 } & $\mathrm{FC} 1$ & 0.67 & 0.45 & \multirow{3}{*}{0.832} & \multirow{3}{*}{0.700} \\
\hline & $\mathrm{FC} 4$ & 0.82 & 0.67 & & \\
\hline & FC5 & 0.61 & 0.37 & & \\
\hline \multirow{3}{*}{ 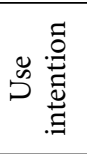 } & BI1 & 0.85 & 0.72 & \multirow{3}{*}{0.903} & \multirow{3}{*}{0.796} \\
\hline & BI2 & 0.78 & 0.61 & & \\
\hline & BI3 & 0.76 & 0.58 & & \\
\hline \multirow{2}{*}{ 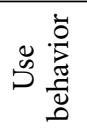 } & UB1 & 0.93 & 0.86 & \multirow{2}{*}{0.803} & \multirow{2}{*}{0.815} \\
\hline & UB2 & 0.70 & 0.49 & & \\
\hline
\end{tabular}

ratio of chi-square value to degree of freedom $\left(\chi^{2} / \mathrm{df}\right)$, goodness of fit index (GFI), adjusted goodness-of-fit index (AGFI), root mean squared residual (RMR), root-meansquare error of approximation (RMSEA), etc. The relevant values are shown in Table 12. Except for GFI and AGFI, values that are close to 0.8 , the other relevant fit indices are within the acceptable range; the other relevant index values are within the standard range, indicating a significant level of fit.

Table 12. Path analysis Comparative fit index (CFI)

\begin{tabular}{|c|c|c|c|c|c|c|}
\hline$\chi^{2}$ & Df & $\chi^{2} /$ Df & GFI & AGFI & RMR & RMSEA \\
\hline 322.916 & 157 & 2.057 & 0.796 & 0.783 & 0.071 & 0.097 \\
\hline
\end{tabular}

\section{Data analysis and results}

\subsection{Hypothesis verification and path analysis}

The AMOS software is used for path analysis. As shown in Figure 7, the path analysis diagram, the path coefficients of the other three variables that affect the combined facet of behavioral intention and facilitating conditions are significant. Only the path coefficient of the combined facet and actual behavior is negative, which will be explained in Chapter 5, in the Conclusion. According to Li (2006), in 
most of the structural equation models used in behavioral science research, one cannot make conclusions about cause and effect using the relevant data. Although the model fit might be good, it does not mean that the model is confirmed to be true. In fact, it is just not confirmed to be false.

The model used in this study is based on the UTAUT framework, so uses the standardization coefficient and significance of the AMOS model to verify whether the hypotheses are established. The structural equations are used to explore the three factors (performance expectancy, effort expectancy and social influence) affecting users' willingness of use to engage with IoT applications, and the structural equations for the two factors (behavioral intention and facilitating conditions) affecting the actual behavior. The hypotheses related to behavioral intention are $\mathrm{H} 1, \mathrm{H} 2$ and $\mathrm{H} 3$, and the hypotheses related to actual behavior are $\mathrm{H} 4$ and $\mathrm{H} 5$, as shown in Figure 8.

(1) H1: User performance expectancy has a positive impact on behavioral intention toward "IoT applications".

The standardization coefficient of the integrated facet of performance expectancy and behavioral intention is 0.45 , and the verification result $\mathrm{P}$ is significant (0.004), indicating that performance expectancy and behavioral intention are significantly and positively correlated, so that hypothesis H1-1 hypothesis. This means that if the user thinks that the use of IoT applications is more helpful for work performance, he/she will be more willing to use these new systems. The verification result $P$ shows that performance expectancy has a significant impact on behavioral intention, indicating that performance expectancy is an important influencing factor.

(2) H2: User effort expectancy has a positive impact on behavioral intention toward "IoT applications".

The standardization coefficient of the integrated facet of effort expectancy and behavioral intention is 0.34 , and the verification result $P$ is significant $(0.021)$,

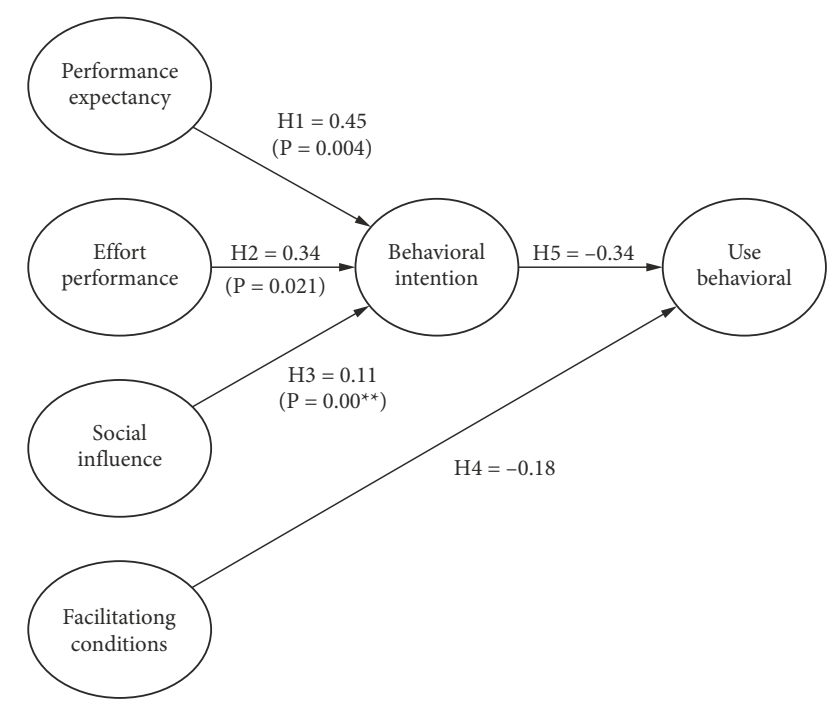

Figure 8. AMOS path analysis result graph in this research indicating that effort expectancy and behavioral intention are significantly and positively correlated, supporting hypothesis $\mathrm{H} 2-1$. This means that if the user thinks that system-related operation of the IoT applications is easier, he/she will be more willing to use this new system. The verification result $P$ shows that effort expectancy has a significant impact on behavioral intention, indicating that effort expectancy is an important influencing factor.

(3) H3: The user's social influence has a positive impact on behavioral intention toward "IoT applications".

The standardization coefficient of the integrated facet of social influence and behavioral intention is 0.11 , and the verification result $\mathrm{P}$ is extremely significant $\left(0.00^{* *}\right)$, indicating that social influence and behavioral intention are significantly and positively correlated, supporting H3.1. This means that if the user perceives that persons with whom that have important relationships believe that the new system should be adopted, this will increase his/her behavioral intention of use. The verification result $P$ shows that social influence has a significant impact on behavioral intention, it is an important influencing factor.

(4) H4: The user's facilitating conditions have a positive impact on their actual behavior toward "IoT applications".

The standardization coefficient of facilitating conditions and actual behavior is -0.18 , indicating a negative correlation between facilitating conditions and actual behavior, so that hypothesis $\mathrm{H} 4$ is not supported. The user thinks that it is not so important that he/she feels they do not have the ability to use the system and the relevant resources of the unit to which he/she belongs do not meet his/her needs, indicating that facilitating conditions are not an important influencing factor.

(5) H5: User behavioral intention toward "IoT applications" has a positive impact on actual behaviors.

The standardization coefficient of behavioral intention and actual behavior is -0.34 , indicating a negative correlation between them, so that hypothesis H5 is not supported. Intention toward the use of IoT applications is not high, indicating that behavioral intention is not an important influencing factor.

\subsection{Analysis of external variables}

\subsubsection{Analysis of gender differences}

Independent sample t-testing was used to analyze and explore whether there were differences gender perceptions of variables such as performance expectancy, effort expectancy, social influence and facilitating conditions. The results show that there is a significant difference between men's and women's perceptions of effort expectancy and facilitating conditions. For example, the mean value of men's effort expectancy $(M=17.9268)$ is significantly higher than that of women $(M=16.090)$; the mean value of men's facilitating conditions $(\mathrm{M}=14.756)$ is also significantly higher than that of women $(M=12.545)$. As 
the mean values reach the level of significance, we further use the univariate analysis method to find the effect value. The effect value is expressed by an eta-squared value $\left(\eta^{2}\right)$, which means that the independent variable "gender" can explain the percentage of variation of the effort expectancy variable. It is found that the eta-squared value of effort expectancy equals 0.084 , indicating that the gender variable can explain $8.4 \%$ of the variation of the effort expectancy variable; the eta-squared value of facilitating conditions equals 0.069 , indicating that gender variable can explain $6.9 \%$ of the variation of the facilitating conditions variable, as shown in Table 13.

Table 13. Independent Sample T-test of gender

\begin{tabular}{|c|c|c|c|c|c|}
\hline Facet & Gender & Average & $P$ value & Differences & $\eta^{2}$ \\
\hline \multirow{2}{*}{$\begin{array}{l}\text { Performance } \\
\text { expectancy }\end{array}$} & Male & 30.9268 & \multirow{2}{*}{0.764} & \multirow{2}{*}{ No } & \multirow{2}{*}{-} \\
\hline & Female & 30.6364 & & & \\
\hline \multirow{2}{*}{$\begin{array}{l}\text { Effort } \\
\text { expectancy }\end{array}$} & Male & 17.9268 & \multirow{2}{*}{0.036} & \multirow{2}{*}{ Yes } & \multirow{2}{*}{0.084} \\
\hline & Female & 16.0909 & & & \\
\hline \multirow{2}{*}{$\begin{array}{l}\text { Social } \\
\text { influence }\end{array}$} & Male & 25.5122 & \multirow{2}{*}{0.684} & \multirow{2}{*}{ No } & \multirow{2}{*}{ - } \\
\hline & Female & 25.0000 & & & \\
\hline \multirow{2}{*}{$\begin{array}{l}\text { Facilitating } \\
\text { conditions }\end{array}$} & Male & 14.7561 & \multirow{2}{*}{0.039} & \multirow{2}{*}{ Yes } & \multirow{2}{*}{0.069} \\
\hline & Female & 12.5455 & & & \\
\hline
\end{tabular}

\subsubsection{One-way analysis of variance}

The one-way analysis of variance was used to analyze the variables of individual attributes of age, application experience, application time and voluntariness in each of the quantitative variables of performance expectancy, effort expectancy, social influence and facilitating conditions. If the result for a construct reached a significant level, posterior comparison was carried out with the Scheffe multiple comparison method to understand the differences in various facets, as shown in Table 14.

(1) The results of the analysis for the variable "age" did not reach the significant difference level of 0.05 for each construct, so no posterior comparison was required. This indicates that age does not cause significant differences in each construct.

(2) The results for the variable "application experience" reached a significant difference level for the constructs of performance expectancy and facilitating conditions. They did not reach a significant difference level of 0.05 for effort expectancy and social influence. This indicates no significant difference in terms of the number of practice hours. When the value of the application experience variable $\mathrm{F}$ is equal to 10.735 , it can explain the $18 \%$ of the variation of the performance expectancy variable; a value of the application experience variable F equal to 4.053 can explain $7.5 \%$ of the variation of the facilitating conditions variable.

(3) (3) The results for the variable of "application time" do not reach the significant level of 0.05 , indicating that usage time does not cause significant differences in each construct.
Table 14. One-way Anova for other analysis

\begin{tabular}{|c|c|c|c|c|c|}
\hline Variables & Facet & F-test & $\begin{array}{c}\mathrm{P} \\
\text { value }\end{array}$ & Scheffe & $\eta^{2}$ \\
\hline \multirow{4}{*}{$\stackrel{8}{4}$} & $\begin{array}{l}\text { Performance } \\
\text { expectancy }\end{array}$ & 0.290 & 0.832 & - & - \\
\hline & $\begin{array}{l}\text { Effort } \\
\text { expectancy }\end{array}$ & 1.694 & 0.181 & - & - \\
\hline & $\begin{array}{l}\text { Social } \\
\text { influence }\end{array}$ & 0.214 & 0.886 & - & - \\
\hline & $\begin{array}{l}\text { Facilitating } \\
\text { conditions }\end{array}$ & 0.476 & 0.701 & - & - \\
\hline \multirow{4}{*}{ 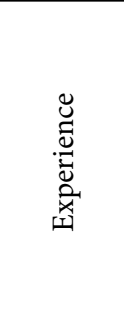 } & $\begin{array}{l}\text { Performance } \\
\text { expectancy }\end{array}$ & 10.735 & 0.002 & have $>$ No & 0.18 \\
\hline & $\begin{array}{l}\text { Effort } \\
\text { expectancy }\end{array}$ & 3.449 & 0.069 & - & - \\
\hline & $\begin{array}{l}\text { Social } \\
\text { influence }\end{array}$ & 1.869 & 0.178 & - & - \\
\hline & $\begin{array}{l}\text { Facilitating } \\
\text { conditions }\end{array}$ & 4.053 & 0.049 & have $>$ No & 0.075 \\
\hline \multirow{4}{*}{ 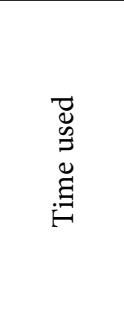 } & $\begin{array}{l}\text { Performance } \\
\text { expectancy }\end{array}$ & 1.207 & 0.317 & - & - \\
\hline & $\begin{array}{l}\text { Effort } \\
\text { expectancy }\end{array}$ & 2.276 & 0.092 & - & - \\
\hline & $\begin{array}{l}\text { Social } \\
\text { influence }\end{array}$ & 1.220 & 0.313 & - & - \\
\hline & $\begin{array}{l}\text { Facilitating } \\
\text { conditions }\end{array}$ & 3.387 & 0.15 & - & - \\
\hline \multirow{4}{*}{ 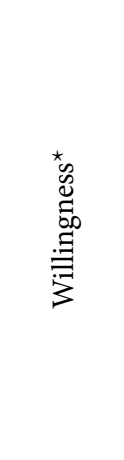 } & $\begin{array}{l}\text { Performance } \\
\text { expectancy }\end{array}$ & 2.975 & 0.041 & $\begin{array}{c}(5)>(4) \\
>(3)> \\
(1)>(2)\end{array}$ & 0.16 \\
\hline & $\begin{array}{l}\text { Effort } \\
\text { expectancy }\end{array}$ & 3.029 & 0.038 & $\begin{array}{c}(5)>(4) \\
>(3)> \\
(1)>(2)\end{array}$ & 0.16 \\
\hline & $\begin{array}{l}\text { Social } \\
\text { influence }\end{array}$ & 8.553 & 0.001 & $\begin{array}{c}(5)>(4) \\
>(3)> \\
(1)>(2)\end{array}$ & 0.35 \\
\hline & $\begin{array}{l}\text { Facilitating } \\
\text { conditions }\end{array}$ & 2.877 & 0.046 & $\begin{array}{c}(5)>(3) \\
>(4)> \\
(1)>(2)\end{array}$ & 0.15 \\
\hline
\end{tabular}

Note: ${ }^{*}$ willingness variables: 1 represents weak willingness while 5 is strong.

(4) The value of the "voluntariness" variable reaches a very significant difference level in the constructs of performance expectancy, effort expectancy, social influence and facilitating conditions, and respondents with higher voluntariness are more aware of each construct than those with lower voluntariness. Further analysis was made of the voluntariness $\mathrm{F}$ value. A performance expectancy variable value equal to 2.975 can explain $16 \%$ of the variation of the performance expectancy variable; a voluntariness $F$ value in the effort expectancy variable equal to 3.029 can explain $16 \%$ of the variation of the effort expectancy variable; a voluntariness $F$ value in the social influence variable equal to 8.553 can explain $35 \%$ of the variation of the social influence variable; a facilitating 
conditions variable $\mathrm{F}$ value equal to 2.877 can explain $15 \%$ of the variation of the facilitating conditions variable.

\subsection{Brief summary}

The main purpose of this study is to explore the factors influencing user willingness to use IoT applications through the unified theory of acceptance and use of technology (UTAUT), and analyze how external factors and moderator variables affect behavioral intention and actual behavior. According to the results of a questionnaire survey and data analysis, some of the hypotheses are not consistent with the theoretical hypotheses. For example, we find that facilitating conditions and behavioral intention have no positive impact on actual behavior; in addition, some of the moderator variables are not consistent with the theoretical hypotheses. Table 15 shows the information on whether the hypotheses are established or not.

Analysis of the impact of moderator variables on the use of IoT applications shows the moderation effects of different conditions (gender, age, experience and voluntariness) on behavioral intention and actual behavior. Only effort expectancy and social influence are affected by gender differences, social influence is affected by volun- tariness differences, and facilitating conditions are affected by differences in experience. The results are described below.

(1) With respect to the impact of the performance expectancy factor on behavioral intention, gender and age have no obvious moderating effect, i.e. whether IoT applications are useful at work will affect willingness of use, and this does not necessarily vary with gender and age differences.

(2) With respect to the impact of the effort expectancy factor on behavioral intention, user gender (male/female) and degree of perception of the effort expectancy factor will affect actual behavior, showing that ease of use of IoT applications is important to the use; IoT applications that are easy to learn and use are very important for the younger age group (20-29 years old) and older age group (40-49 years old); in addition, in terms of application experience, all groups pay attention to the ease of use of IoT applications.

(3) With respect to the impact of the social influence factor on behavioral intention, the results show that, for both male and female users, the degree of perception of social influence will affect their actual behavior; in addition, the older age, middle

Table 15. Result of the research hypothesis

\begin{tabular}{|c|c|}
\hline Research Hypothesis & Result \\
\hline H1: User performance expectancy has a positive impact on the behavioral intention toward the "IoT applications" & support \\
\hline $\begin{array}{l}\text { H1.1: User performance expectancy has a positive impact on the behavioral intention toward the "IoT applications" } \\
\text { due to the moderation of gender differences }\end{array}$ & not support \\
\hline $\begin{array}{l}\text { H1.2: User performance expectancy has a positive impact on the behavioral intention toward the "IoT applications" } \\
\text { due to the moderation of age differences }\end{array}$ & not support \\
\hline H2: User effort expectancy has a positive impact on the behavioral intention toward the "IoT applications" & support \\
\hline $\begin{array}{l}\text { H2.1: User effort expectancy has a positive impact on the behavioral intention toward the "IoT applications" due to } \\
\text { the moderation of gender differences }\end{array}$ & support \\
\hline $\begin{array}{l}\text { H2.2: User effort expectancy has a positive impact on the behavioral intention toward the "IoT applications" due to } \\
\text { the moderation of age differences }\end{array}$ & not support \\
\hline $\begin{array}{l}\text { H2.3: User effort expectancy has a positive impact on the behavioral intention toward the "IoT applications" due to } \\
\text { the moderation of experience differences }\end{array}$ & not support \\
\hline $\begin{array}{l}\text { H3: The social influence a user is subject to has a positive impact on his/her behavioral intention toward the "IoT } \\
\text { applications" }\end{array}$ & support \\
\hline $\begin{array}{l}\text { H3.1: The social influence a user is subject to has a positive impact on his/her behavioral intention toward the "IoT } \\
\text { applications" due to the moderation of gender differences }\end{array}$ & support \\
\hline $\begin{array}{l}\text { H3.2: The social influence a user is subject to has a positive impact on his/her behavioral intention toward the "IoT } \\
\text { applications" due to the moderation of age differences }\end{array}$ & not support \\
\hline $\begin{array}{l}\text { H3.3: The social influence a user is subject to has a positive impact on his/her behavioral intention toward the "IoT } \\
\text { applications" due to the moderation of experience differences }\end{array}$ & not support \\
\hline $\begin{array}{l}\text { H3.4: The social influence a user is subject to has a positive impact on his/her behavioral intention toward the "IoT } \\
\text { applications" due to the moderation of voluntariness differences }\end{array}$ & support \\
\hline H4: User facilitating conditions have a positive impact on the actual behaviors toward the "IoT applications" & not support \\
\hline $\begin{array}{l}\text { H4.1: User facilitating conditions have a positive impact on the actual behaviors toward the "IoT applications" due to } \\
\text { the moderation of gender differences }\end{array}$ & not support \\
\hline $\begin{array}{l}\text { H4.2: User facilitating conditions have a positive impact on the actual behaviors toward the "IoT applications" due to } \\
\text { the moderation of experience differences }\end{array}$ & support \\
\hline H5: User behavioral intention toward the "IoT applications" has a positive impact on actual behaviors & not support \\
\hline
\end{tabular}


age and highly experienced user groups are more impacted by the opinions of influential people on their use of the system; in terms of voluntariness, highly willing users have a higher intention to use IoT applications.

(4) It is found that the effect of enabling conditions on the user's actual use of the IoT application is related to their age and experience. According to the results, the older age group (40-49 years old) is more concerned with the support of the company in terms of relevant policies, technology and equipment than the middle and younger age group. It is hoped that the organization can provide appropriate assistance in use.

\section{Conclusions}

The main purpose of this study is to explore the factors influencing user's willingness to use IoT applications through the unified theory of acceptance and use of technology (UTAUT), and analyze how external factors and moderator variables can affect behavioral intention and actual behavior. The results show that there are three main factors that affect user willingness, namely, performance expectancy, effort expectancy and social influence, indicating that whether the users feel that IoT applications can help improve their work performance, whether these applications are easy to learn and use, and whether influential people around them support their use of the system are the most important factors affecting user acceptance. It is thus suggested that when IoT applications are introduced, the organization should not only pay attention to whether the system can improve the work performance, but also ensure that the user feels it is easy to use the applications. However, the scale of IoT applications is still small. There is still much room for the development of related facilities. If the selectivity and diversity of future applications could increase, and the relevant conditions of use are met, positive results from user application of IoT in the construction industry can be predicted.

Based on the results obtained from data analysis, usage behavior is positively correlated with continuity of use. In the construction industry, in view of work assistance with the electronic information system and increasing use of Building Information Model (BIM), the introduction of IoT applications seems to be imperative; however, in terms of practical applications, the IoT is still in the development stage. Considering that technological developments are immature and unstable, and the construction industry is a high risk business with low profits, the use of new information technology systems will surely increase the operating cost. Given that the public sector is often interested in minimizing costs by adopting the lowest possible standards, the additional cost of using IoT applications conflicts with the interests of manufacturers. In addition, the benefits of IoT applications in the construction industry are still not clear. While the IoT has proven effective in other industries, the construction industry may be dif- ferent than those that generate high revenue through IoT applications.

This research was aimed at personnel in the construction. However, the industries included in the construction industry are very extensive, and the decision-making powers of the respondents varied. At present, there is still a lack of in-depth discussion about behavioral intention and actual behavior. Follow-up researchers could compare and discuss other areas that are relevant but limited, or conduct surveys for personnel within a specific work area, so as to provide a reference for real-world use.

There are many definitions and measurement methods for behavioral intention. Based on the time constraints, only the UTAUT was used to verify the data for analysis. Different research models and an increase in the number of samples could be used to explore the topic more deeply and to develop more suitable theoretical models, which will help predict user intention and behavior in the use of technology and better understand the relations between them.

\section{Acknowledgements}

This research is grateful for the academic support of Taiwan's participating experts and construction practitioners.

\section{Author contributions}

Jieh-Haur Chen contributor roles: supervision, Nguyen Thi Thu Ha contributor roles: writing-original draft, Hsing-Wei Tai contributor roles: writing-review \& editing, Chao-An Chang contributor roles: writing-original draft.

\section{Disclosure statement}

Article does not have any competing financial, professional, or personal interests from other parties.

\section{References}

Al-Fuqaha, A., Guizani, M., Mohammadi, M., Aledhari, M., \& Ayyash, M. (2015). Internet of Things: A survey on enabling technologies, protocols, and applications. IEEE Communications Surveys Tutorials, 17(4), 2347-2376.

https://doi.org/10.1109/COMST.2015.2444095

Agarwal, R., \& Prasad, J. (1997). A conceptual and operational definition of personal innovativeness in the domain of information technology. Information Systems Research, 9, 204-224. https://doi.org/10.1287/isre.9.2.204

Ajzen, I. (1985). From intentions to actions: A theory of planned behavior. In J. Kuhl, \& J. Beckman (Eds.), Action control: from cognition to behaviour (pp. 11-39). Springer. https://doi.org/10.1007/978-3-642-69746-3_2

Ajzen, I. (1991). The theory of planned behavior. Organizational Behavior and Human Decision Processes, 50(2), 179-211. https://doi.org/10.1016/0749-5978 (91)90020-T

Ajzen, I., \& Fishbein, M. (1975). Attitude-behavior relations: A theoretical analysis and review of empirical research. Psychological Bulletin, 84(5), 888-918.

https://doi.org/10.1037/0033-2909.84.5.888 
Ajzen, I., \& Fishbein, M. (1980). Understanding attitudes and predicting social behavior (Paperback ed.). Prentice-Hall.

Al-Khaldi, M. A., \& Wallace, R. S. O. (1999). The influence of attitudes on personal computer utilization among knowledge workers: the case of Saudi Arabia. Information \& Management, 36(4), 185-204.

https://doi.org/10.1016/S0378-7206(99)00017-8

Armitage, C. J., \& Conner, M. (2001). Efficacy of the Theory of Planned Behaviour: A meta-analytic review. British Journal of Social Psychology, 40(4), 471-499.

https://doi.org/10.1348/014466601164939

Alaa, M., Zaidan, A. A., Zaidan, B. B., Talal, M., \& Kiah, M. L. M. (2017). A review of smart home applications based on Internet of Thing. Journal of Network and Computer Applications, 97, 48-65. https://doi.org/10.1016/j.jnca.2017.08.017

Bagozzi, R. P., \& Yi, T. (1988). On the evaluation of structural equation models. Journal of the Academy of Marketing Science, 16(1), 74-94. https://doi.org/10.1007/BF02723327

Bhargav, D., Silvain, K., Ergo, P., Jan, H., Vishal, S., Kary, F., \& Lauri, K. (2015). Intelligent products: Shifting the production control logic in construction (with Lean and BIM). In Proceedings of the 23rd Annual Conference of the International Group for Lean Construction (pp. 341-350). Perth, Australia.

Bozionelos, N. (1996). Psychology of computer use: XXXIX. Prevalence of computer anxiety in British managers and professionals. Psychological Reports, 78(3), 995-1002.

https://doi.org/10.2466/pr0.1996.78.3.995

Chen, G., Wang, E., Sun, X., \& Lu, Y. (2016). An intelligent approval system for city construction based on cloud computing and big data. International Journal of Grid and High Performance Computing, 8(3), 57-69.

https://doi.org/10.4018/IJGHPC.2016070104

Chi, B., Meng, H., Zhai, K., Zhai, G., \& Liu, Y. (2017). Big data in urban construction archives and urban management: Detected underground pipes alignment with urban construction records. In IEEE International Conference on Big Knowledge (pp. 173-178). https://doi.org/10.1109/ICBK.2017.53

Davis, F. D. (1989). Perceived usefulness, perceived ease of use, and user acceptance of information technology. MIS Quarterly, 13(3), 319-339. https://doi.org/10.2307/249008

Fornell, C., \& Larcker, D. F. (1981). Evaluating structural equation models with unobservable variables and measurement error. Journal of Marketing Research, 18, 39-50. https://doi.org/10.1177/002224378101800104

Gates, B. (1995). The road ahead. Viking Penguin.

Glaeser, E. L., Kominers, D., Luca, M., \& Naik, N. (2018). Big data and big cities: The promises and limitations of improved measures of urban life. Economic Inquiry, 56(1), 114-137. https://doi.org/10.1111/ecin.12364

Gubbia, J., Buyya, R., Marusica, S., \& Palaniswami, M.(2013). Internet of Things (IoT): A vision, architectural elements, and future directions. Future Generation Computer Systems, 29(7), 1645-1660. https://doi.org/10.1016/j.future.2013.01.010

Hair, J., Anderson, R., Tatham, R., \& Black, W. (1998). Multivariate data analysis (5th ed.). Prentice Hall Publishing.

Jöreskog, K. G. (1993). Testing structural equation models. In K. A. Bollen, \& J. S. Long (Eds.), Testing structural equation models (pp. 294-316). Sage.

Jia, M., Komeily, A., Wang, Y., \& Srinivasan, R. S. (2019). Adopting Internet of Things for the development of smart buildings: A review of enabling technologies and applications. Automation in Construction, 101, 111-126.

https://doi.org/10.1016/j.autcon.2019.01.023
Karahanna, E., Straub, D. W., \& Chervany, N. L. (1999). Information technology adoption across time: A cross-sectional comparison of pre-adoption and post-adoption beliefs. Management Information Systems, 23(2), 183-213. https://doi.org/10.2307/249751

Lee, I., \& Lee, K. (2015). The Internet of Things (IOT): Applications, investments, and challenges for enterprises. Business Horizons, 58(4), 431-440.

https://doi.org/10.1016/j.bushor.2015.03.008

Leo, M., Battisti, F., Carli, M., \& Neri, A. (2014). A federated architecture approach for Internet of Things security. In Proceedings of 2014 Euro Med Telco Conference (EMTC). Naples, Italy. https://doi.org/10.1109/EMTC.2014.6996632

Lin, J., Yu, W., Zhang, N., Yang, X., Zhang, H., \& Zhao, W. (2017). A survey on Internet of Things: Architecture, enabling technologies, security and privacy, and applications. IEEE Internet of Things Journal, 4(5), 1125-1142. https://doi.org/10.1109/JIOT.2017.2683200

Li, M. N. (2006). Introduction to structural equation model software AMOS and application compilation. Taipei Psychology Press.

Li, C. Z.; Xue, F., Shen, G. Q., Xu, X., \& Luo, L. (2016). SWOT analysis and Internet of Things-enabled platform for prefabrication housing production in Hong Kong. Automation in Construction, 57, 74-87. https://doi.org/10.1016/j.habitatint.2016.07.002

Li, C. Z., Xue, F., Li, X., Hong, J., \& Shen, G. Q. (2018). An Internet of Things-enabled BIM platform for on-site assembly services in prefabricated construction. Automation in Construction, 89, 146-161.

https://doi.org/10.1016/j.autcon.2018.01.001

Lu, W., Chen, X., Peng, Y., \& Shen, L. (2015). Benchmarking construction waste management performance using big data resources. Conservation and Recycling, 105, 49-58.

https://doi.org/10.1016/j.resconrec.2015.10.013

Lu, W., Chen, X., Ho, D. C. W., \& Wang, H. (2016). Analysis of the construction waste management performance in Hong Kong: The public and private sectors compared using big data. Journal of Cleaner Production, 112(1), 521-531. https://doi.org/10.1016/j.jclepro.2015.06.106

Lynott, P. P., \& McCandless, N. J. (2000). The impact of age vs. life experience on the gender role attitudes of women in different cohorts. Journal of Women \& Aging, 12(1-2), 5-21. https://doi.org/10.1300/J074v12n01_02

Mahmoud, R., Yousuf, T., Aloul, F., \& Zualkernan, I. (2015). Internet of things (IoT) security: Current status, challenges and prospective measures. In Proceedings of 2015 10th International Conference for Internet Technology and Secured Transactions (ICITST) (pp. 336-341). London, UK. https://doi.org/10.1109/ICITST.2015.7412116

McKinsey Global Institute. (2015). The Internet of Things: Mapping the value beyond the hype.

Miorandi, D., Sicari, S., \& Chlamtac, I. (2012). Internet of things: vision, applications and research challenges. Ad Hoc Networks, 10(7), 1497-1516. https://doi.org/10.1016/j.adhoc.2012.02.016

Moore, G. C., \& Benbasat, I. (1991). Development of an instrument to measure the perceptions of adopting an information technology innovation. Information Systems Research, 2(3), 173-239. https://doi.org/10.1287/isre.2.3.192

Ray, P. P. (2016). A survey on Internet of Things architectures. Journal of King Saud University - Computer and Information Sciences, 30(3), 291-319.

https://doi.org/10.1016/j.jksuci.2016.10.003 
Sethi, P., \& Sarangi, S. R. (2017). Internet of Things: Architectures, protocols, and applications. Journal of Electrical and Computer Engineering, Article ID 9324035.

https://doi.org/10.1155/2017/9324035

Szajna, B. (1996). Empirical evaluation of the revised technology acceptance model. Management Science, 42, 85-92. https://doi.org/10.1287/mnsc.42.1.85

Taylor, S., \& Todd, P. A. (1995a). Assessing IT usage: The role of prior experience. MIS Quarterly, 19(4), 561-570. https://doi.org/10.2307/249633

Taylor, S., \& Todd, P. A. (1995b). Decomposition and crossover effects in the theory of planned behavior: A study of consumer adoption intentions. International Journal of Research in Marketing, 12(2), 137-155. https://doi.org/10.1016/0167-8116(94)00019-K

Taylor, S., \& Todd, P. A. (1995c). Understanding information technology usage: a test of competing models. Information Systems Research, 6(2), 144-176. https://doi.org/10.1287/isre.6.2.144

Tan, L., \& Wang, N. (2010). Future internet: The Internet of Things. In Proceedings of 2010 3rd International Conference on Advanced Computer Theory and Engineering (ICACTE). Faridabad, India. https://doi.org/10.1109/ICACTE.2010.5579543

Thompson, R. L., Higgins, C. A., \& Howell, J. M. (1991). Personal computing: Toward a conceptual model of utilization. MIS Quarterly, 15(1), 125-143. https://doi.org/10.2307/249443

Venkatesh, V., \& Davis, F. D. (2000). A theoretical extension of the technology acceptance model: Four longitudinal field studies. Management Science, 46(2), 186-204. https://doi.org/10.1287/mnsc.46.2.186.11926

Venkatesh, V., Morris, M. G., Davis, G., \& Davis, F. D. (2003). User acceptance of information technology: Toward a unified view. MIS Quarterly, 27(3), 425-478.

https://doi.org/10.2307/30036540

Viswannathen, B. M. (2015). Aligning IoT with construction industry [Post]. LinkedIn. https://www.linkedin.com/pulse/ aligning-iot-construction-industry-baalaje-ms-viswanathan/

Weiser, M., Gold, R., \& Brown, J. S. (1999). The origins of ubiquitous computing research at PARC in the late 1980s. IBS Systems Journal, 38(4), 693-696. https://doi.org/10.1147/sj.384.0693

Wu, M., Lu, T. J., Ling, F. Y., Sun, J., \& Du, H. Y. (2010). Research on the architecture of Internet of Things. In Proceedings of 2010 3rd International Conference on Advanced Computer Theory and Engineering (ICACTE). Chengdu, China.

Xu, G., Li, M., Chen, C., \& Wei, Y. (2018). Cloud asset-enabled integrated IoT platform for lean prefabricated construction. Automation in Construction, 93, 123-134. https://doi.org/10.1016/j.autcon.2018.05.012

Zhong, R. Y., Peng, Y., Xue, F., Fang, J., Zou, W., Luo, H., Ng, S. T., Lu, W., Shen, G. Q. P., \& Huang, G. Q. (2017). Prefabricated construction enabled by the Internet-of-Things. Automation in Construction, 76, 59-70.

https://doi.org/10.1016/j.autcon.2017.01.006 